\title{
The relationship between talent management and talented employees' performance: empirical investigation in the Vietnamese banking sector
}

\author{
Nhan Truong Thanh Dang ${ }^{a, b^{*}}$, Quynh Thi Nguyen ${ }^{b}$ and Van Dung $\mathbf{H a}^{a}$
}

${ }^{a}$ Banking University Ho Chi Minh City, Vietnam

${ }^{b}$ RMIT University, Vietnam

\begin{tabular}{l}
\hline C H R O N I C L E \\
\hline Article history: \\
Received: February 15, 2020 \\
Received in revised format: \\
March 162020 \\
Accepted: March 16, 2020 \\
Available online: \\
March 16, 2020 \\
\hline Keywords: \\
Talent management \\
Talented employees' performance \\
Banking sector \\
Vietnam
\end{tabular}

\section{A B S T R A C T}

Although managers of various banks and institutions in Vietnam have established several policies to attract talented employees, talent management is still an emerging issue. This gives rise for a need of an empirical study which explores the relationship between talent management (TM) practices and talented employees' performance. Hence this study fills the gap by applying the survey technique in the quantitative method with the main objective of examining the relationship between $\mathrm{TM}$ and the four dimensions of employee performance; namely task, contextual, adaptive and counterproductive through affective commitment. A total of 375 questionnaires was targeted for distribution to talented employees in 10 banks in Vietnam. The findings show that although TM practices positively support employee performance (task, contextual and adaptive), they also reduce counterproductive behaviours. Also, affective commitment partially mediates the relationship between $\mathrm{TM}$ and the four dimensions of employee performance. The result of the study has some practical implications for managers and banks implementing and intending to implement TM practices. Managers and banks can design and implement TM practices with the aim to increase positive employee performance behaviours, reduce counterproductive behaviours and benefit from positive affective commitment through the implementation of TM practices.

C) 2020 by the authors; licensee Growing Science, Canada

\section{Introduction}

Talent management (TM) has also been found to be significantly related to employee performance (Luna-Arocas \& Morley, 2015). In particular, employee performance has been considered as a multi-dimensional concept made up of task, context, and adaptive and counterproductive behaviours (Motowidlo et al., 1997; Koopmans et al., 2011; Yoon, 2019). Although there is a growing acceptance of the concepts of TM and the multi-dimensionality of employee performance (Motowidlo, 2000; Koopmans et al., 2011; Mensah, 2015), there has not been much empirical research clearly studying how TM relates to the various dimensions of employee performance. Luna-Arocas and Morley (2015) attempted this but limited their study to one dimension. There have also been suggestions about how TM could lead to employee performance, but most of these are conceptual (Collings \& Mellahi, 2009; Mensah, 2015) or practitioner papers (Gubman, 1998) that were based on anecdotal evidence without empirical tests. Recently, Mensah et al. (2016) conducted a study to investigate the relationship between TM and four dimensions of employee performance with the evidence emanating from Ghana. The lack of research on such issue in other geographic locations demonstrates that there is still limited empirical knowledge of how TM influences various dimensions of employee performance. Vietnam, being a developing country in South East Asia, has enjoyed sustained economic growth since 1986 following the adoption of Đổi Mới (Renovation). The country has received an astronomical amount of attention from foreign companies (Le et al., 2019). Scholars mentioned that almost all companies in Vietnam, both foreignbased and local, have already been struggling to conquer this issue of talent (Vo, 2009; Vo \& Hannif, 2012; Tran \& Truong, 
2017). Given the above, TM becomes a vital factor for organizations in Vietnam, including banks, necessitating to develop a business strategy. In terms of the banking sector in Vietnam, the US Bilateral Trade Agreement (USBTA) in 2001, together with Vietnam's participation in the World Trade Organisation (WTO) since 2007, have provided many opportunities and challenges for the country's banking sector (Nguyen \& Doan, 2016). The Vietnamese authorities were committed to liberalizing the banking system by 2010 , according to WTO regulations. With such commitments, foreign banks have been granted the right and opportunity to expand their activities in the Vietnamese banking sector in terms of having better accessibility to a greater share of its capital (Bellocq \& Silve, 2008). Tremendous pressure and fierce competition from foreign banks in the marketplace have been the impetus behind a systematic reform of not only state-owned banks, but also of commercial banks (Nguyen \& Doan, 2016). With almost every bank having several branches and transaction offices across 64 provinces in the country, there has been a significant demand for professional staff in this industry, leading to a serious competitive race of recruiting and retaining qualified employees and talents among the financial institutions (Nguyen \& Doan, 2016). Therefore, several banks in Vietnam have paid special attention towards reforming their HRM systems in order to improve their effectiveness in achieving higher-labour productivity, including raising incomes and formulating proper policies to retain their staff. Although managers of various banks and institutions have established several policies to attract talented employees, TM is still an emerging issue in Vietnam. This could be evidenced through a number of limited researches conducted in relation to this topic in the country's context. Generally, such research mainly investigated the manner with which companies can attract and/or retain Vietnamese talent (Froese et al., 2010; Kim et al., 2012; Nguyen \& Doan, 2016). This gives rise for a need of an empirical study which explores the relationship between TM practices and talented employees' performance. Hence this study fills the gap through the objective: To evaluate the relationship between TM practices and the four dimensions of talented employees' performance (task, contextual, adaptive and counterproductive).

With the above objective, this research attempts to significantly contribute to the development of TM from, both, the theoretical and practical perspectives. Theoretically, this research is expected to contribute to the development of the TM-related literature, in general, and TM in the banking sector, in particular, with a focus on Vietnam's context, a region where very little research on TM has been geared towards. This would contribute to the development of global TM theories and can be used as a research reference for scholars with interest in this topic. Practically, the research raises the banks' awareness of the vitality of TM practices and based on such provides practical implications.

\section{Literature review}

\subsection{Relationship between TM and employee performance}

TM has been found to be significantly related to employee performance (Luna-Arocas \& Morley, 2015). Luna-Arocas and Morley (2015) attempted to study this linkage this but limited their study to one dimension of performance. There have also been suggestions about how TM could lead to employee performance, but most of these are conceptual (Collings \& Mellahi, 2009; Mensah, 2015) or practitioner papers (Gubman, 1998) that were based on anecdotal evidence without empirical tests. Recently, Mensah et al. (2016) conducted a study to investigate the relationship between TM and the four dimensions of employee performance with evidence emanating from Ghana. The lack of research on such an issue in other geographic locations demonstrates that there is still limited empirical knowledge of how TM influences various dimensions of employee performance. TM implementation in a business environment can have strategic effects on an organization. According to Gelens et al. (2014) and Björkman et al. (2013), employees regarded as talents often demonstrate higher work effort, leading to higher performance, than those who were not identified as such. Luna-Arocas and Morley (2015) found a positive relationship between TM and job performance. Generally, their research concluded that employee performance is a consequence of TM. However, these studies treat employee performance as if it were a monothematic concept. Although the popularity of the concepts of TM and the multi-dimensionality of employee performance is growing (Motowidlo, 2000; Koopmans et al., 2011; Mensah, 2015), empirical research has not clearly studied how TM relates to the various dimensions of employee performance (Mensah, 2015). Employee performance has been considered as a multi-dimensional concept made up of task, contextual, adaptive and counterproductive behaviours (Motowidlo et al., 1997; Pulakos et al., 2000; Koopmans et al., 2011). Task performance includes patterns of behaviour that deliver direct support for the organisation's core technical processes (Van Scotter et al., 2000). Task performance covers actions that are part of the formal reward system, and addresses the requirements as specified in the job descriptions (Williams \& Karau, 1991). Contextual performance, on the other hand, refers to behaviours that are not directly related to the job, but support the psychological and social contexts in which task activities are performed (Borman \& Motowidlo, 1993; Koopmans et al., 2011). Adaptive performance is the ability to adapt to changes in work tasks, such as being flexible and versatile (Pulakos et al., 2000; Griffin et al., 2007). Counterproductive behaviour is a non-task behaviour that has negative consequences for both the organisation and the individual (Viswesvaran \& Ones, 2000; Rotundo \& Sackett, 2002). It is expected that talented employees would be competent in their job (task performance), be able to commit extra effort on the task (contextual performance), be innovative and generate new ideas (adaptive performance) and not engage in behaviours that harm their organisation (Mensah, 2015). From the social exchange theory (SET) perspective, an organisation acts in positive ways towards employees, creating reciprocity so that employees generally respond in positive ways that are beneficial to the organization (Blau, 1964). When an organisation invests in TM practices and applies SET, talented employees would feel obligated to reciprocate with positive behaviours, such as high performance (Mensah, 2015). Similarly, from the perspective of the signalling theory (ST), TM practices communicate messages to talented employees to perform 
(Spence, 1978; Gelens et al., 2015). Therefore, investments in TM practices send a signal (Spence, 1978) to talented employees to perform as long as these investments are preferred by them. The combinatory insight from SET and ST helps to explain the relationship and mechanisms through which TM leads to the four dimensions of employee performance (Mensah, 2015). However, the relationship between TM and performance is not direct and is mediated by immediate outcomes of TM, which can be collectively termed as TM outputs. Although the purpose of TM is to ensure high employee performance and ultimately organizational performance, it nonetheless leads to TM outputs which serve as antecedents (Mensah, 2015). One significant TM output mediator, which has been discussed in previous studies, is affective commitment (Collings and Mellahi, 2009; Oehley \& Theron, 2010; Chami-Malaeb \& Garavan, 2013; Vural et al., 2012; Mensah, 2015, Luna-Arocas \& Morley, 2015; Gelens et al., 2015). As stated by Oehley and Theron (2010), affective commitment is an intervening variable between TM and employee performance. Likewise, Luna-Arocas and Morley (2015) proposed that affective commitment may be used as a mediating variable in the TM-employee performance relationship. SET and ST also help in explaining the mediating relationship between TM and employee performance. As a result, when TM practices trigger employee attitudes, such as affective commitment, such attitudes then lead to employee performance (Mensah, 2015). Specifically, employee work attitudes of affective commitment are related to all four dimensions of employee performance. The relationship between employee work attitudes and performance has been proven by previous studies such as Luna-Arocas and Morley (2015), Mensah (2015), Mensah (2016). Therefore, satisfied and committed talented employees are more likely to put in more discretionary effort in the performance of their duties. At the same time, such employees will not engage in counterproductive behaviours that will negatively affect the well-being of their organisation and colleagues (Mensah, 2016).

\subsection{Proposed hypotheses}

As mentioned previously, Luna-Arocas and Morley (2015), Gelens et al. (2014) and Björkman et al. (2013) found a positive relationship between TM and job performance. Commonly, these studies concluded that employee performance is a consequence of TM. In this research, it is expected that a talented employee would be competent in their job (task performance), be able to commit extra effort on the task (contextual performance) and be innovative and generate new ideas (adaptive performance). Besides, TM is expected to be negatively related to counterproductive behaviours, because most talented employees may not engage in behaviours that harm their organisation (Mensah, 2015). Applying the SET, when an organisation invests in TM practices, talented employees are likely to feel obligated to reciprocate with positive behaviours, such as high performance. Similarly, the ST suggests that TM practices send signals to talented employees to perform. Based on the preceding discussion, we hypothesise that:

$\mathrm{H}_{1}$. A positive relationship exists between TM and (a) task performance, (b) contextual performance and (c) adaptive performance, (d) but a negative relationship with counterproductive behaviours.

Additionally, studies have found a relationship between TM and employee work attitudes, especially affective commitment (Björkman et al., 2013; Chami-Malaeb \& Garavan, 2013; Gelens et al., 2015; Luna-Arocas \& Morley, 2015). BethkeLangenegger et al. (2011) found that TM initiatives increased commitment in their study of 138 Swiss companies. Similarly, in the Lebanese context, Chami-Malaeb and Garavan (2013) found that talent development practices had a positive relationship with affective commitment. According to the study of Björkman et al. (2013) of 769 managers and professionals in nine Nordic multinational corporations, employees who perceived that they had been identified as "talented" were more likely to be associated with commitment than those who were either perceived that they had not been identified or did not know whether they had been identified (Björkman et al., 2013). In addition, Gelens et al. (2015), in their comparative study of designated and non-designated high potentials, found that employees designated as high potentials experienced more affective commitment than the ones non-designated as high potentials. Therefore, the research hypothesizes the following:

\section{H2. A positive relationship exists between TM and affective commitment.}

Besides, several studies have found a relationship between work attitudes and employee performance, which asserts that satisfied and committed employees are likely to apply more efforts leading to employee performance. In particular, affective commitment has been the most widely studied, as it has been proven to have consistent relationships with organisational outcomes, such as performance, attendance and retention (Meyer \& Allen, 1997). The relationship is such that committed employees are more likely to put in their maximum effort and, hence, are considered as performing employees (Meyer and Allen, 1997). Likewise, Khan et al. (2010) found that employee commitment had a positive and significant impact on performance. In other words, the willingness to exercise effort was mostly considered as a direct outcome of affective commitment. Therefore, the research makes the following hypothesis:

H3. A positive relationship exists between affective commitment and (a) task performance, (b) contextual performance and (c) adaptive performance (d) but a negative relationship exists with counterproductive behaviours.

Collings and Mellahi (2009) and Mensah (2015), in their respective conceptual frameworks, argued that the relationship between TM and performance was not straight and that the relationship was mediated by TM outputs. One of the significant TM outputs which mediates the relationship between TM and performance is affective commitment (Collings and Mellahi, 2009; Mensah, 2015). Similarly, Oehley and Theron (2010) argued that affective commitment was an intervening variable between TM and employee performance. Luna-Arocas and Morley (2015) proposed that affective commitment be used as a 
mediating variable in the TM employee performance relationship. The SET and the ST also help in explaining the mediating relationship between TM and employee performance. In other words, when TM practices trigger employee attitudes, these attitudes then lead to employee performance. Accordingly, the following hypothesis is proposed:

H4. Affective commitment will mediate the relationship between TM and (a) task performance, (b) contextual performance, (c) adaptive performance and (d) counterproductive behaviours.

\section{Research Methodology}

\subsection{Sample selection}

This research is conducted within the context of the Vietnamese banking industry, and specifically focuses on public (stateowned), private and foreign banks. The list of all banks operating in the country were acquired from the State Bank of Vietnam (2019). The selected banks are well-known in Vietnam, and have more than 1,000 employees. Recent studies suggest that the required sample size depends on the number of factors and the number of variables associated with each factor (Bandalos \& Boehm-Kaufman, 2008). Hatcher (1994) recommended that the number of subjects should be 5 times larger than the number of observed variables. There were 59 questions which represented 59 observed variables. Therefore, the sample size should be calculated as: $n=59 \times 5=295$. Consequently, a total of 375 questionnaires was targeted for distribution to talented employees, with a target response rate projected to reach approximately $70 \%-80 \%$. The list was obtained from the HR departments of 10 banks. All respondents had to meet the required criteria. The main objective of this method was to examine the relationship between TM and the four dimensions of employee performance: task, contextual, adaptive and counterproductive through affective commitment. The questionnaire was developed based on the Likert-Scale measurement, tested in previous studies. Such employees consisted of staff in various positions, such as recently graduated/ new/ junior/ senior staff/ manager.

\subsection{Survey technique}

The survey technique was used in the quantitative method with the main objective of examining the relationship between TM and the four dimensions of employee performance - task, contextual, adaptive and counterproductive - through affective commitment. TM practices are measured according to five items related to the practices employed in strategically managing banks' talent pools. Instruments from previous studies (Chadee \& Raman, 2012; Raman et al., 2013; Luna-Arocas \& Morley, 2015) were examined for the authors to formulate the necessary elements to capture such practices. In this study, the task, contextual and adaptive performances, as well as counterproductive behaviours, are measured according to the scale developed by Koopmans et al. (2012). Besides, affective commitment is measured using the scales developed by Allen and Meyer (1990). As mentioned above, a total of 375 questionnaires were distributed to talented employees, with the target response rate projected to reach approximately $70 \%-80 \%$. Participants of the surveys were talented employees from the selected banks, as mentioned in the qualitative research part. The list of talented employees was obtained from the HR departments of 10 selected banks. Such employees consisted of staff at various positions, such as recently graduated/ new/ junior/ senior staff/ manager. In order to complement the above response rate, the authors attempted to take advantage of their personal connections with graduate students whom they had previously instructed and who are currently working in selected banks, as well as their personal connections with bank managers. The authors also conducted pilot studies to test the questionnaires with about 10 respondents, including experts, professionals and academics. This helps to refine the data collection plans, with respect to both the content of the data and the procedures (Yin, 2009).

\subsection{Quantitative Analysis}

Data processing procedures are stated as follows: firstly, data are cleaned and solved missing values; secondly, SPSS is used to explore data, test normality and reliability of instruments, correlation among variables, and run EFA and regression analysis; and lastly, AMOS is employed to confirm the model (structural equation modelling).

\section{Empirical results}

\subsection{Information of survey subjects}

To study the relationship between managing talents and the performance of employees in banks, author conducted survey questionnaires to individuals who are employees working at the banks. The answers of the survey respondents were collected by the author; the survey questionnaire is developed on a 5-level Likert scale. The author received the survey questionnaires, checked the invalid forms, performed cleaning, encoded necessary information in the survey, conducted data entry and data analysis using SPSS 20, AMOS 20 software. The total number of survey questionnaires sent to the talented employees in the selected banks was 375 . In fact, 302 forms were received, gaining $80.53 \%$, of which there were 295 valid forms and 7 invalid forms, which were still blank with lots of information, so it was not guaranteed to be reliable. Invalid forms were excluded before analysing by SPSS, AMOS software. Finally, 295 questionnaires were used for the study, reaching 78.67\%. Therefore, the sample selected was 295 valid and informative, consistent with the requirements and representative of the sample. This should ensure the implementation of the study. 
Table 1

Summary of factors after using Cronbach's Alpha

\begin{tabular}{llll}
\hline Factor & $\begin{array}{l}\text { Before Cronbach's Alpha } \\
\text { Number of items }\end{array}$ & Cronbach's Alpha value & $\begin{array}{c}\text { After Cronbach's Alpha } \\
\text { Number of items }\end{array}$ \\
\hline Talent management (TM) & 6 & 0,903 & 5 (Eliminate TM6) \\
Affective commitment (AC) & 8 & 0,738 & 3 (Eliminate AC2, AC4, AC6, AC7, AC8) \\
Task performance (TP) & 13 & 0,924 & 4 (Eliminate TP5, TP6, TP7, TP8, TP9, TP10, TP11, TP12, TP13) \\
Contextual performance (CP) & 14 & 0,915 & 4 (Eliminate CP2, CP6, CP7, CP8, CP9, CP10, CP11, CP12, CP13, \\
Adaptive performance (AP) & 8 & 0,933 & 4 (Eliminate AP5, AP6, AP7, AP8) \\
Counterproductive work behaviour (CWB) & 10 & 0,921 & 4 (Eliminate CWB3, CWB6, CWB7, CWB8, CWB9, CWB10) \\
\hline
\end{tabular}

Source: SPSS analysis results

Based on the reliability analysis of the measurement scales, we can conclude that all 59 variables (including variables of factors) used in the analysis meet the requirements, except for TM6 (included in factor Talent management ); AC2, AC4, AC6, AC7, AC8 (included in Affective commitment); TP5, TP6, TP7, TP8, TP9, TP10, TP11, TP12, TP13 (included in Task performance); CP2, CP6, CP7, CP8, CP9, CP10, CP11, CP12, CP13, CP14 (included in Contextual performance), AP5, AP6, AP7, AP8 (included in Adaptive performance) and CWB3, CWB6, CWB7, CWB8, CWB9, CWB10 (included in Counterproductive work behaviour). Therefore, the remaining ( 24 variables) ensure the reliability to perform the next analysis.

\subsection{Exploratory Factor Analysis}

After preliminarily evaluating the scales of measurement based on Cronbach's Alpha values, all 24 variables meeting reliability requirements are put into EFA. EFA plays a role in discovering the scale structure of factors including TM (Talent management), AC (Affective Commitment), TP (Task Performance), CP (Contextual Performance), AP (Adaptive Performance) and CWB (Counterproductive Work Behavior). After ensuring EFA procedures, the factors will be tested to clean data. The results of running EFA on 24 variables of the scales of factors indicated that the KMO value is 0,702 and Sig. is 0,000 which means that the KMO value ensures the suitability of exploratory factor analysis and the significance level of the data used in EFA. The Bartlett Chi-square value is 9.204,711 with a significance of 0,000 which is less than 0,05. At the same time, the average variance extracted is $79,697 \%$ which is relatively high. As a result, 79,697\% of variation is explained by 6 factors; the factors are extracted and acceptable. The analysis is stopped when the sixth factor is extracted with an eigenvalue of 1,078 which is greater than 1 (this proves that the variables are arranged into 6 factor groups). Consequently, it can be concluded that the observed variables are correlated with each other within the populations and the model with 6 factors needs regression analysis. According to the Pattern Matrix, the results show that all the coefficients are satisfied (all factor loadings are above 0.5) and are separated into 6 groups, including: TM, AC, TP, CP, AP and CWB. As a result, after performing EFA, all the variables met analysis requirements. Therefore, the total number of variables are 24 and separated into 6 groups of factors. They are TM, AC, TP, CP, AP and CWB.

\subsection{Analysing Confirmatory Factor Analysis (CFA)}

After performing the explanatory factor analysis, the author implements CFA to measure the goodness of fit between the model and the collected data. People often use Chi-square (CMIN), Chi - square adjusted to the degree of freedom (CMIN/df), comparative fit index (CFI_Comparative Fit Index), Tucker and Lewis index (TLI_Tucker and Lewis Index), RMSEA (Root Mean Square Error Approximation), NFI, RMR. A few things to note about these indicators are as follows: The model is considered to be appropriate for the data when testing. The chi - square test produces a P-value $<0.05$ (which is $5 \%$ ). Values of Chi - square/df less than 3 are considered good and less than 5 are considered acceptable. Values of GFI, CFI, TLI, NFI greater than 0.95 are considered very good, greater than 0.9 are considered good and greater than 0.8 are considered acceptable. RMSEA, RMR values below 0.05 are considered very good, ranging from 0.05 to 0.1 are considered good and greater than 0.1 are considered as not good enough. The author performs CFA by using AMOS, with the purpose of testing the impact of the factors TM, AC, TP, CP, AP and CWB on one another. To analyse CFA, the author uses the EFA results with 6 main factors, namely TM, AC, TP, CP, AP and CWB. The results of the CFA show that the value of Chi-square/df is 3,739, less than 5 compared to the value of Sig. (P-value) which is 0,000 and less than 0,05 (less than 5\%). This ensures the statistical significance; along with other values such as GFI which is 0,816 and larger than 0,8 ; TLI which is 0,919 and bigger than 0,9 , CFI which is 0,935 and bigger than 0,9 , NFI which is 0,914 and bigger than 0,9 , RMSEA which is 0,097 and less than 0,1 and RMR which is 0,043 and less than 0,5 . Therefore, it can be said that the model fits the data.

Table 2

Composite reliability and total variance extracted of factors

\begin{tabular}{llll}
\hline Comp & Factor & Composite reliability & Variance extracted \\
\hline 1 & Talent management & 0.882 & 0.699 \\
2 & Affective commitment & 0.694 & 0.733 \\
3 & Task performance & 0.938 & 0.798 \\
4 & Contextual performance & 0.901 & 0.695 \\
5 & Adaptive performance & 0.943 & 0.812 \\
6 & Counterproductive work behaviour & 0.929 & 0.775 \\
\hline
\end{tabular}


At the same time, all the standardized estimates are found to be larger than 0.5 ensuring the statistical significance so the convergence validity of the factors are obtained. Consequently, based on the results of CFA analysis, the author achieved the results from the model with 6 main factors. They are TM, AC, TP, CP, AP and CWB.

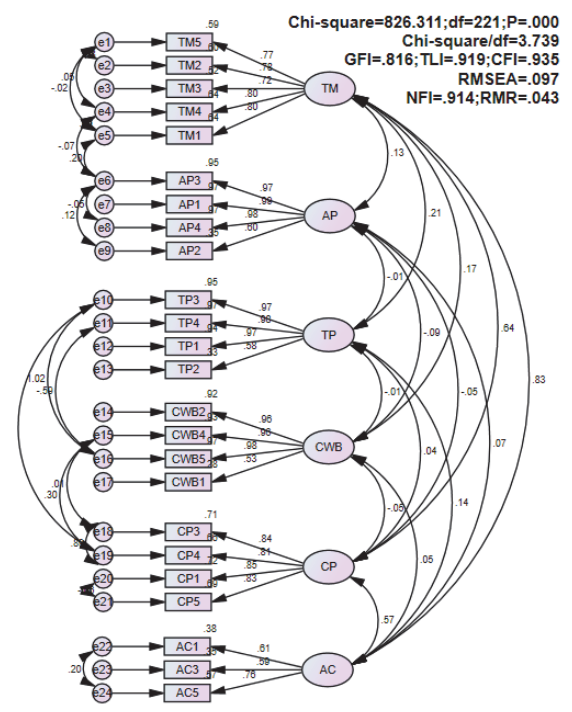

Fig. 1. CFA analysis results following standardized coefficients

In addition, the authors calculated composite reliability and total variance in order to evaluate the reliability of scales. The results show that the reliability and total extracted variance of all factors are above 0.5 . It means that the reliability of the factors are ensured when analysing.

\section{Table 3}

Calculating P-values for correlation coefficients

\begin{tabular}{|c|c|c|c|c|c|c|c|}
\hline STT & & Corr & & Estimate & SE & $\mathrm{CR}$ & $\mathrm{P}$ \\
\hline 1 & TM & $\leftrightarrow$ & AP & 0.133 & 0.058 & 14.974 & 0.00 \\
\hline 2 & TM & $\leftrightarrow$ & TP & 0.215 & 0.057 & 13.759 & 0.00 \\
\hline 3 & $\mathrm{TM}$ & $\leftrightarrow$ & CWB & -0.168 & 0.058 & 20.281 & 0.00 \\
\hline 4 & $\mathrm{TM}$ & $\leftrightarrow$ & $\mathrm{CP}$ & 0.640 & 0.045 & 8.020 & 0.00 \\
\hline 5 & TM & $\leftrightarrow$ & $\mathrm{AC}$ & 0.832 & 0.032 & 5.184 & 0.00 \\
\hline 6 & AP & $\leftrightarrow$ & $\mathrm{TP}$ & 0.005 & 0.058 & 17.032 & 0.00 \\
\hline 7 & AP & $\leftrightarrow$ & CWB & 0.093 & 0.058 & 15.593 & 0.00 \\
\hline 8 & AP & $\leftrightarrow$ & $\mathrm{CP}$ & 0.051 & 0.058 & 16.265 & 0.00 \\
\hline 9 & AP & $\leftrightarrow$ & $\mathrm{AC}$ & 0.068 & 0.058 & 15.990 & 0.00 \\
\hline 10 & $\mathrm{TP}$ & $\leftrightarrow$ & CWB & 0.014 & 0.058 & 16.879 & 0.00 \\
\hline 11 & $\mathrm{TP}$ & $\leftrightarrow$ & $\mathrm{CP}$ & 0.039 & 0.058 & 16.462 & 0.00 \\
\hline 12 & TP & $\leftrightarrow$ & $\mathrm{AC}$ & 0.136 & 0.058 & 14.928 & 0.00 \\
\hline 13 & CWB & $\leftrightarrow$ & $\mathrm{CP}$ & 0.054 & 0.058 & 16.217 & 0.00 \\
\hline 14 & CWB & $\leftrightarrow$ & $\mathrm{AC}$ & -0.053 & 0.058 & 18.050 & 0.00 \\
\hline 15 & $\mathrm{CP}$ & $\leftrightarrow$ & $\mathrm{AC}$ & 0.569 & 0.048 & 8.971 & 0.00 \\
\hline
\end{tabular}

Source: The author's calculations

Furthermore, the results show that all P-values are less than 0.05 (which is $5 \%$ ) so each correlation coefficients is different from 1 at a $95 \%$ confidence level. Therefore, the values have discriminant validity.

The results of CFA analysis show that the model fits the data, the scales ensure the reliability and the values have discriminant validity, ensuring the analysis of linear structural equation model (SEM).

\subsection{SEM shows the relationship between the factors.}

Based on the CFA analysis results, there are 6 main factors including TM, AC, TP, CP, AP and CWB. To perform SEM analysis to show the relationship between the factors including TM, AC, TP, CP, AP and CWB, the authors converted the model which was built from the results of CFA analysis into SEM. After performing SEM analysis, the author collected the result of SEM analysis as Fig. 2. The results of CFA analysis show that the results of the model fit the data well. This is shown by indices such as the value of Chi-square/df is 3,726 which is less than 5 with the P-value $=0,000<0.05$ (which is less than $5 \%$ ). This ensures statistical significance. GFI is 0.831 , less than 0.8 ; TLI is 0.918 , greater than 0,9 ; CFI is 0.937 , greater than 0.9 ; NFI is 0.916 , greater than 0.9; RMSEA is 0.096 , less than 0,1 and RMR is 0,052 , less than 0.1 . 


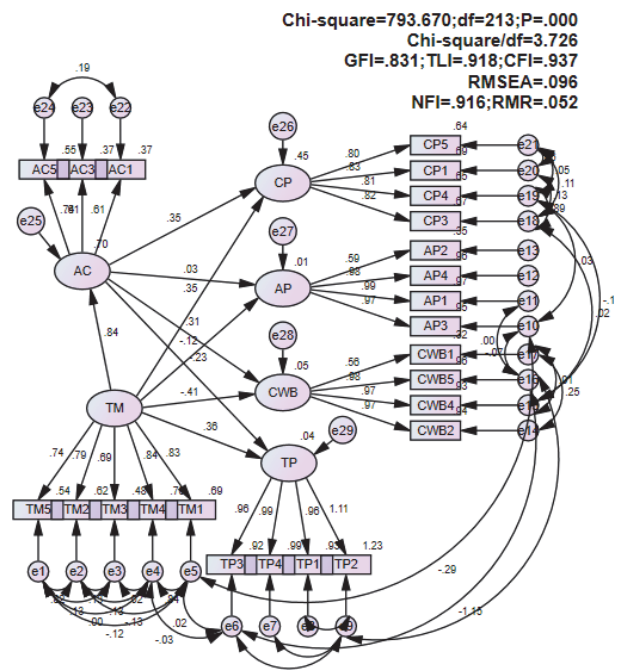

Fig. 2. SEM shows the relationship between the factors (following standardized coefficients)

Source: AMOS analysis results

Table 4

SEM analysis and coefficients

\begin{tabular}{|c|c|c|c|c|c|c|c|c|c|c|c|c|}
\hline \multicolumn{3}{|c|}{ Relationship } & \multicolumn{4}{|c|}{ SEM analysis } & \multicolumn{2}{|c|}{$\begin{array}{l}\text { SEM (standardized coef- } \\
\text { ficients) }\end{array}$} & \multicolumn{4}{|c|}{ Bootstrap results } \\
\hline & & & Est. & S.E. & C.R. & $P$ & Est. & Est. (diagram) & Est. & Bias & SE-Bias & $C R$ \\
\hline $\mathrm{AC}$ & $\leftarrow$ & TM & 0.691 & 0.095 & 7.257 & 0.000 & 0.837 & 0.84 & 0.837 & 0.020 & 0.051 & 0.392 \\
\hline $\mathrm{CP}$ & $\leftarrow$ & $\mathrm{AC}$ & 0.593 & 0.301 & 1.969 & 0.049 & 0.349 & 0.35 & 0.349 & 0.024 & 0.064 & 0.375 \\
\hline AP & $\leftarrow$ & $\mathrm{AC}$ & 0.047 & 0.274 & 0.173 & 0.003 & 0.030 & 0.03 & 0.030 & 0.001 & 0.054 & 0.019 \\
\hline CWB & $\leftarrow$ & $\mathrm{AC}$ & -0.451 & 0.294 & -1.537 & 0.004 & -0.122 & -0.12 & -0.122 & 0.005 & 0.074 & 0.676 \\
\hline $\mathrm{TP}$ & $\leftarrow$ & $\mathrm{AC}$ & 0.376 & 0.262 & 1.431 & 0.002 & 0.306 & 0.31 & 0.306 & 0.003 & 0.074 & 0.041 \\
\hline $\mathrm{CP}$ & $\leftarrow$ & TM & 0.490 & 0.238 & 2.060 & 0.039 & 0.349 & 0.35 & 0.349 & 0.031 & 0.075 & 0.413 \\
\hline $\mathrm{AP}$ & $\leftarrow$ & TM & 0.158 & 0.217 & 0.727 & 0.007 & 0.233 & 0.23 & 0.233 & 0.024 & 0.055 & 0.436 \\
\hline CWB & $\leftarrow$ & TM & -0.502 & 0.238 & -2.110 & 0.035 & -0.412 & -0.41 & -0.412 & 0.003 & 0.005 & 0.600 \\
\hline TP & $\leftarrow$ & TM & 0.476 & 0.233 & 2.046 & 0.041 & 0.358 & 0.36 & 0.358 & 0.005 & 0.006 & 0.833 \\
\hline
\end{tabular}

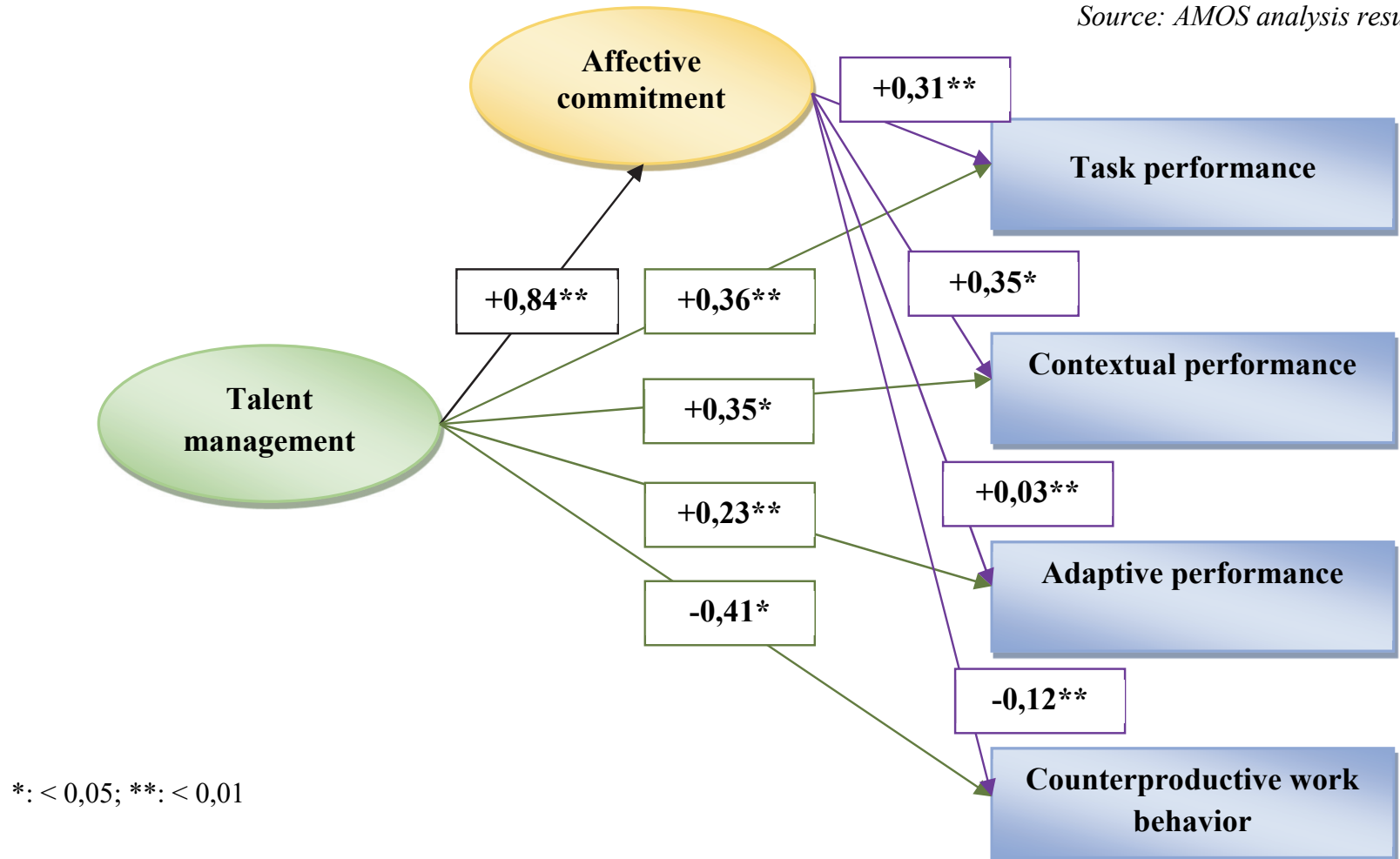

Fig. 3. Linear SEM analysis results reflecting the relationship between talent management and employees' performance in banks 
At the same time, the results of SEM analysis and the P-values of the relationship between the factors show the TM factor is statistically significant in its impact on TP, CP, AP and CWB because the P-Values of their relationships are $0.041 ; 0.039$; $0.007 ; 0.035$, respectively and less than 0,05 (which is less than 5\%). The TM factor is statistically significant when it has an impact on AC because the P-Value of the relationship is 0,000 less than 0.05 (which is less than $5 \%$ ). The AC factor is statically significant in its impact on TP, CP, AP and CWB because the P-Values of their relationship are 0.002; 0.049; 0.003; 0.004 , respectively and less than 0.05 (which is less than 5\%). In examining regression coefficients between the factors, it is shown that all regression coefficients are above 0 . This indicates the relationship between factors are positive (positive impact), except the negative relationship (negative impact) between AC and CWB and between TM and CWB. The result of the Bootstrap test shows that the absolute value of CR is less than 2 so it can be concluded that the standard deviation is very small which indicates that SEM analysis results are reliable.

Table 5

Summary of model results

\begin{tabular}{|c|c|c|c|}
\hline STT & Hypothesis & Content & Conclusion \\
\hline 1 & H1 & $\begin{array}{l}\text { Talent management has a positive relationship with (a) Task performance, (b) Contextual performance, } \\
\text { (c) Adaptive performance, (d) but has a negative relationship with Counterproductive work behaviour }\end{array}$ & Acceptable \\
\hline 2 & $\mathrm{H} 2$ & There is a positive relationship between Talent management and Affective commitment & Acceptable \\
\hline 3 & $\mathrm{H} 3$ & $\begin{array}{l}\text { Affective commitment has a positive relationship with (a) Task performance, (b) Contextual perfor- } \\
\text { mance, (c) Adaptive performance, (d) but has a negative relationship with Counterproductive work be- } \\
\text { haviour }\end{array}$ & Acceptable \\
\hline 4 & $\mathrm{H} 4$ & $\begin{array}{l}\text { Affective commitment coordinates the relationship between Talent management and (a) Task perfor- } \\
\text { mance, (b) Contextual performance, (c) Adaptive performance, (d) Counterproductive work behaviour }\end{array}$ & Acceptable \\
\hline
\end{tabular}

It can be seen that TM (Talent management) has a positive impact on Task performance, Contextual performance and Adaptive performance; meanwhile, it has a negative impact on CWB (Counterproductive work behaviour). Especially, TM was found to have the strongest positive impact on task performance (with an increase by 1 of TM, Task performance increases by 0.36 ). This implies that if TM is designed and implemented effectively, the most recognizable outcome would be the improvement of employees' task performance. Such is seen as the biggest motivation for banks to pay more attention to TM activities. Besides, affective commitment plays a role in coordinating/mediating the relationship between Talent management and Task performance, Contextual performance, Adaptive performance, Counterproductive work behaviour, because Talent management has a statistical significance in positively affecting Affective commitment (H2 hypothesis) and Affective commitment has a statistical significance in impacting (a) Task performance, (b) Contextual performance, (c) Adaptive performance, (d) Counterproductive work behaviour (H3a,b,c,d hypotheses). The finding of the relationship between TM and talented employees' performance is in line with previous studies such as Luna-Arocas and Morley (2015) and Mensah et al. (2016). It was found that TM does not only help to increase positive performance but also reduces counterproductive behaviours. Therefore, the implementation of TM will lead to employee performance in terms of core job tasks, contextual behaviours, creativity and innovativeness, whereas, at the same time, reducing negative behaviours at work. These findings can also be supported by the SET to the extent that when organisations invest in TM practices, talented employees will compensate the organisation with performance. The findings can also be explained by ST perspective, indicating that investment in TM practices sends a signal to employees in the talent pool to perform.

Consistent with previous studies such as (Chami-Malaeb and Garavan, 2013; Luna-Arocas and Morley, 2015; Gelens et al., 2015; Mensah et al., 2016), it was found that TM is positively related to affective commitment. The implementation of TM is likely to encourage positive work attitude of affective commitment. This finding provides support for the SET, suggesting that when organisations invest in their employees in terms of TM practices and professional development; the employees would be likely to reciprocate their organisational investments in positive ways. As per the findings, employee work attitude of affective commitment is correlated to all the four dimensions of employee performance. This finding also supports previous studies that have found a relationship between employee work attitudes and employee performance (Luna-Arocas and Morley, 2015; Mensah et al., 2016; Jalal et al., 2019). In specific, committed talented employees are more likely to put in more discretionary effort to the performance of their responsibilities. Simultaneously, such employees will not engage in counterproductive behaviours that will negatively affect the operations of their organisations and colleagues. The affective commitment partially mediates the relationship between TM and all the dimensions of employee performance. The finding apparently supports the SET in that TM practices generate reciprocation in terms of performance via positive employee work attitudes. Additionally, the positive impact that Talent management has on Task performance, Contextual performance and Adaptive performance can provide implications for how banks should view and manage talent. That task performance is viewed from the output perspective (result orientation) and, in other words, the high performance approach. Contextual performance and adaptive performance can be considered as input factors (ability orientation) and, in other words, the high potential approach. The quantitative analysis shows that TM helps to increase high performance factors as well as high potential factors. In long term, high potential (ability) factors reasonably contribute to the high performance achievement. Therefore, an appropriate TM scheme should be designed not only for high performers but also for high potentials so that the high potentials can be adequately equipped to have a higher chance to become high performers. 


\section{Conclusion}

The findings have shown that although TM practices positively support employee performance (task, contextual and adaptive), they also reduce counterproductive behaviours. TM practices are also positively related to employee work attitudes of affective commitment. As previously mentioned, the result has shown that affective commitment had positive relationships with task, contextual and adaptive performance but a negative relationship existed with counterproductive behaviours. Last but not least, affective commitment partially mediated the relationship between TM and the four dimensions of employee performance. To recapitulate, TM does not only increase positive employee performance behaviours but also reduces counterproductive behaviours through the partial mediating role of affective commitment. This study contributes to the literature by examining how TM practices influence and relate to four dimensions of employee performance with the focus on the Vietnamese banking sector. Besides, the study contributes to the TM literature by examining the mediating mechanisms through which TM practices lead to employee performance in the context where limited research on TM focuses on.

The result of the study has some practical implications for managers and banks implementing and intending to implement TM practices. First, managers and banks can design and implement TM practices with the aim to increase positive employee performance behaviours and reduce counterproductive behaviours. Second, banks in particular and organisations in general can benefit from positive work attitudes of affective commitment through the implementation of TM practices. Lastly, managers and organisations should note that effective TM practices should be implemented not only for high performers but also for high potentials so that the high potentials can be adequately equipped to have a higher chance to become high performers.

The study still involves some limitations which can provide suggestions for further research. First, future research should examine this study's model through a longitudinal research design to determine the causal links more explicitly. Second, even though this study has identified the importance of affective commitment as partially mediating the relationship between TM practices and employee performance, some other work attitude variables such as job satisfaction, employee engagement and motivation can be considered. Furthermore, future research should compare results from employees viewed as talents and non-talents to explore whether TM is solely responsible for the relationships found in this study. Finally, further research is recommended to use subjective data either from managers or other stakeholders. Multiple ratters can be used to collect data on employee performance.

\section{References}

Bandalos, D. L., \& Boehm-Kaufman, M. R. (2008). Four Common Misconceptions in Exploratory Factor Analysis, in Charles, E. L., Vandenberg, R. J. (Eds.), Statistical and Methodological Myths and Urban Legends: Doctrine, Verity and Fable in the Organizational and Social Sciences. Routledge Taylor \& Francis Group, New York, pp. 81- 108.

Bellocq, F. X., \& Silve, A. (2008). The banking system of Vietnam after the accession to WTO: Transition and its challenges (No. 77). Working Paper.

Björkman, I., Ehrnrooth, M., Mäkelä, K., Smale, A., \& Sumelius, J. (2013). 'Talent or not? employee reactions to talent identification. Human Resource Management, 52(2), 195-214.

Blau, P. (1964). 1964 Exchange and Power in Social Life. John Wiley \& Sons Inc.

Borman, W.C., \& Motowidlo, S. (1993). Expanding the Criterion Domain to Include Elements of Contextual Performance, in Schmitt, N., Borman. W. C. (Eds.), Personnel Selection in Organizations. Jossey-Bass, San Francisco, pp. $71-98$.

Chadee, D., \& Raman, R. (2012). External knowledge and performance of offshore IT service providers in India: The mediating role of talent management. Asia Pacific Journal of Human Resources, 50(4), 459-482.

Chami-Malaeb, R., \& Garavan, T. (2013). Talent and leadership development practices as drivers of intention to stay in lebanese organisations: The Mediating Role of Affective Commitment. The International Journal of Human Resource Management, 24(21), 4046-4062.

Collings, D.G., \& Mellahi, K. (2009). Strategic talent management: A review and research agenda. Human Resource Management Review, 19(4), 304-313.

Froese, F.J., Vo, A., \& Garrett, T.C. (2010). Organizational attractiveness of foreign-based companies: A country of origin perspective. International Journal of Selection and Assessment, 18(3), 271-281.

Gelens, J., Dries, N., Hofmans, J., \& Pepermans, R. (2015). Affective commitment of employees designated as talent: Signalling perceived organisational support. European Journal of International Management, 9(1), 9-27.

Gelens, J., Hofmans, J., Dries, N., \& Pepermans, R. (2014). Talent management and organisational justice: Employee reactions to high potential identification. Human Resource Management Journal, 24(2), 159-175.

Griffin, M. A., Neal, A., \& Parker, S. K. (2007). A new model of work role performance: Positive behavior in uncertain and interdependent contexts. Academy of Management Journal, 50(2), 327-347.

Gubman, E. L. (1998). The Talent Solution: Aligning Strategy and People to Achieve Extraordinary Results. New York: McGraw-Hill.

Hatcher, L. (1994). A Step-by-Step Approach to Using the SAS(R) System for Factor Analysis and Structural Equation Modeling $\left(1^{\text {st }}\right.$ ed). Cary, North Carolina: SAS Institute.

Jalal, R. N. U. D., Zeb, N., \& Fayyaz, U. E. R. (2019). The effect of personality traits on employee job satisfaction with moderating role of Islamic work ethics. Journal of Asian Finance, Economics and Business, 6(2), $161-171$. 
Kim, S., \& McLean, G. N. (2012). Global talent management: Necessity, challenges, and the roles of HRD. Advances in Developing Human Resources, 14(4), 566-585.

Koopmans, L., Bernaards, C. M., Hildebrandt, V. H., Schaufeli, W. B., De Vet Henrica, C., \& Van Der Beek, A. J. (2011). Conceptual frameworks of individual work performance: A systematic review. Journal of Occupational and Environmental Medicine, 53(8), 856-866.

Koopmans, L., Bernaards, C., Hildebrandt, V., van Buuren, S., Van Der Beek, A. J., \& De Vet, H. C. (2012). Development of an individual work performance questionnaire. International Journal of Productivity and Performance Management, 62(1), 6-28.

Le, N. H., Duy, L. V. Q., \& Ngoc, B. H. (2019). Effects of foreign direct investment and human capital on labour productivity: Evidence from Vietnam. Journal of Asian Finance, Economics and Business, 6(3), 123-130.

Luna-Arocas, R., \& Morley, M. J. (2015). Talent management, talent mindset competency and job performance: The mediating role of job satisfaction. European Journal of International Management, 9(1), 28-51.

Mensah, J. K. (2015). A “Coalesced Framework" of talent management and employee performance: For further research and practice. International Journal of Productivity and Performance Management, 64(4), 544-566.

Mensah, J. K., Bawole, J. N. \& Wedchayanon, N (2016). Unlocking the "Black Box" in the talent management employee performance relationship: Evidence from Ghana. Management Research Review, 39 (12), 1546-1566.

Meyer, J. P., \& Allen, N. J. (1997). Commitment in the Workplace: Theory, Research, and Application, Thousand Oaks, California: SAGE Publications.

Motowidlo, S. J. (2000). Some basic issues related to contextual performance and organizational citizenship behavior in human resource management. Human Resource Management Review, 10(1), 115-126.

Motowildo, S. J., Borman, W. C., \& Schmit, M. J. (1997). A theory of individual differences in task and contextual performance. Human Performance, 10(2), 71-83.

Nguyen, N. M., \& Doan, T. H. (2016). Determinants of talent retention in commercial banks in the southeast Vietnam. International Journal of Business and Applied Social Science, 2(8).

Oehley, A. M., \& Theron, C. C. (2010). The development and evaluation of a partial talent management structural model. management dynamics. Journal of the Southern African Institute for Management Scientists, 19(3), 2-28.

Pulakos, E. D., Arad, S., Donovan, M. A., \& Plamondon, K. E. (2000). Adaptability in the workplace: Development of a taxonomy of adaptive performance. Journal of Applied Psychology, 85(4), 612-624.

Raman, R., Chadee, D., Roxas, B., \& Michailova, S. (2013). Effects of partnership quality, talent management, and global mindset on performance of offshore IT service providers in India. Journal of International Management, 19(4), 333-346.

Rotundo, M., \& Sackett, P. R. (2002). The relative importance of task, citizenship, and counterproductive performance to global ratings of job performance: a Policy-Capturing Approach. Journal of Applied Psychology, 87(1), 66-80.

Spence, M. (1978). Job Market Signaling. Uncertainty in Economics (pp. 281, 283-306). Amsterdam: Elsevier.

State Bank of Vietnam. (2019). List of Commercial Banks in Vietnam. State Bank of Vietnam. Retrieved July 2019, from $<$ https://www.sbv.gov.vn/webcenter/portal $/ \mathrm{vi} / \mathrm{menu} / \mathrm{fm} / \mathrm{htctctd} / \mathrm{nh} / \mathrm{nhtm} / \mathrm{nhtmcp}$ ?centerWidth $=80 \% 25 \&$ leftWidth $=20 \% 25 \&$ rightWidth $=0 \% 25 \&$ showFooter $=$ false \&showHeader $=$ false $\&$ adf.ctrl-state $=$ apd0rsvgz $41 \&$ afrLoop $=3443245761110000>$.

Tran, K. D., \& Truong, T. L. A. (2017). A Framework of significant human resource management practices in Vietnam. Journal of Economic Development, 24(4), 46-63.

Van Scotter, J., Motowidlo, S. J., \& Cross, T. C. (2000). Effects of task performance and contextual performance on systemic rewards. Journal of Applied Psychology, 85(4), 526-535.

Viswesvaran, C., \& Ones, D. S. (2000). Perspectives on models of job performance. International Journal of Selection and Assessment, 8(4), 216-226.

Vo, A. (2009). The Transformation of Human Resource Management and Industrial Relations in Vietnam, Amsterdam: Elsevier.

Vo, A., \& Hannif, Z. (2012). The transfer of training and development practices in Japanese subsidiaries in Vietnam. Asia Pacific Journal of Human Resources, 50(1), 75-91.

Vural, Y., Vardarlier, P., \& Aykir, A. (2012). The effects of using talent management with performance evaluation system over employee commitment. Procedia-Social and Behavioral Sciences, 58, 340-349.

Williams, K. D., \& Karau, S. J. (1991). Social loafing and social compensation: The effects of expectations of co-worker performance. Journal of Personality and Social Psychology, 61 (4), 570-581.

Yin, R.K. (2009). Case Study Research: Design and Methods (4 $4^{\text {th }}$ ed.). Los Angeles and London: SAGE Publications.

Yoon, K. H., Kim, B.Y., \& EOM, J. G. (2019). The effects of job crafting on career success of multinational corporations' employees. Journal of Asian Finance, Economics and Business, 6(4), 213-225.

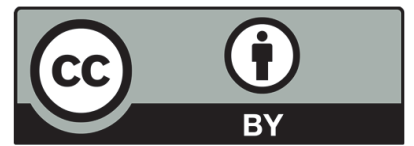

(C) 2020 by the authors; licensee Growing Science, Canada. This is an open access article distributed under the terms and conditions of the Creative Commons Attribution (CC-BY) license (http://creativecommons.org/licenses/by/4.0/). 